\title{
Y Neslinin Örgüt Ortamındaki Davranış Farklılıklarının Analizi
}

Murat ÇEMBERCi, İstanbul Ticaret Üniversitesi Uygulamalı Bilimler Fakültesi, mcemberci@ticaret.edu.tr

Melike Kıvanç SUDAK, İstanbul Ticaret Üniversitesi, Meslek Yüksekokulu, mksudak@ticaret.edu.tr

Saim AŞÇı, i̇stanbul Ticaret Üniversitesi,Meslek Yüksekokulu, sasci@ticaret.edu.tr

Sabri Öz, İstanbul Ticaret Üniversitesi, Meslek Yüksekokulu, soz@ticaret.edu.tr

Mustafa Emre CiVELEK, İstanbul Ticaret Üniversitesi, Meslek Yüksekokulu, ecivelek@ticaret.edu.tr

ÖZET Dijital Kuşak olarak bilinen $Y$ neslinin son yıllarda örgütlerdeki etkinliği giderek artmaktadır. Birçok sektörde faaliyet gösteren farklı ölçeklerdeki örgütlerde yönetsel pozisyonlarda görev almaya başlamışlardır. Bu durum, örgüt içindeki Y neslinin diğerlerinden iş görme anlayışı açısından farklı olduklarına dair bir algıya sebep olmuştur. Bu araştırmada, öncelikle $Y$ neslinin örgüt ortamında diğer çalışanlardan farklılaştı̆̆ı boyutlarm belirlenmesi ve bu boyutlarm hangi yönde farklılaştıklarının analizi amaçlanmıştır. Yapılan analiz sonucunda, Y neslinin çoklu görev, sosyal medya kullanımı, takım çalışmasına yatkınlık, eğlenerek çalışma ve çalışan bağlılığı boyutlarında diğerlerinden farklı oldukları bilimsel olarak ispatlanmıştır.

Anahtar Kelimeler: Dijital Kuşak, Y Nesli, İş Görme Anlayışı

\section{Analysis of Behavior \\ or Differences of Generation $Y$ in Organizational Environment}

ABSTRACT Effectiveness of generation $Y$ that is known as digital generation is continuously
increasing in recent years. They have begun to take responsibilities in the managerial
positions of the organizations in different scales and sectors. This situation has led to the
perception that generation $Y$ working in organizations is different from others in terms of
business behaviors. In this study, primarily, it is aimed that the determinations of the
dimensions that generation $Y$ differentiate from others in organization environment and
analysis the differentiation in the direction of these dimensions. According to the result of 
analysis, it has been scientifically proven that generation $Y$ is different from others in these dimensions: multi-tasking, use of social media, ability to team work, working joyfully and employee commitments.

Keywords: Digital Generation, Generation Y, Business Behavior

\section{Giriş̧}

Bu çalışma Y nesline mensup çalışanların örgüt ortamında davranışlarının yorumlanması ve bu kuşaktaki çalışanlara uygun yönetim tarzlarının belirlenmesini amaçlamaktadır. Araştırma kapsamında ele alınacak temel araştırma sorusu: "Y nesli örgüt ortamında diğerlerinden hangi boyutlarda davranış açısından farklılaşmaktadır?". Bu araştırma sorusu günümüzde akademik çevrelerde araştırma bekleyen önemli bir alan olarak ortaya çıkmaktadır. Dolayısıyla, çalışmanın bu amaca hizmet eden yönü ile literatüre katkı sağlayacağı düşünülmektedir.

Türk Dil Kurumu "kuşak" kelimesini "birbirine yakın yıllarda doğmuş, aynı dönemin koşullarını, dolayısıyla birbirine yakın sorunları paylaşmış, benzer sorumlulukları üstlenmiş bireyler topluluğu" olarak tanımlamaktadır. Farklı kuşakların varlığına ilişkin yaygın kabul gören çalışmalardan biriKupperschmidt tarafından yapılmıştır. Bu çalışmada kişilerin gelişim dönemlerinde yaşanan önemli olayların etkisiyle farklı kuşaklar oluştuğu ileri sürülmüştür. Kupperschmidt kişilerin gençlik dönemlerinde yaşadıkları bu ortak deneyimler çerçevesinde bazı davranış kalıpları gösterdiklerini ileri sürmüştür (Kupperschmidt, 2000). Howe ve Strauss'a göre ise aşağıda listelenen nedenler neslin oluşumunda doğum tarihinden daha önemlidir (Howe ve Strauss, 2000).

Algılanan Üyelik: Ergenlik ve genç yetişkinlik dönemlerinde bir neslin üyesi olduğuna dair kendiliğinden oluşan algıdır.

Genel İnançlar ve Davranışlar:Bir nesli karakterize eden tutumlar(aileye, iş yaşamına, politikaya vs. karşı) ve davranışlar ( iş, evlilik, çocuk gibi konularda yapılan seçimler).

Tarih içeresideki yer:Neslin oluşmaya başladığı dönemde (ergenlik ve genç yetişkinlik dönemleri) meydana gelen tarihsel önemli olaylardır.

Y nesli mensupları ebeveynlerinin yarattığı korumacı ve güvenli ortamda büyümüşlerdir. (Howe ve Strauss, 2000). Doğdukları dönem boşanma oranlarının arttığı, doğum kontrolünün yaygınlaştığı döneme rastladığından bu neslin çocukları ebeveynleri tarafından çok istenen çocuklardır ve ebeveynleri için çok değerlidirler. Ebeveynlerine bağlılıkları buna bağlanmaktadır. Y nesli mensupları yetiştirilme tarzları sebebiyle benmerkezci ve kendilerini aşırı önemseyen bireylerdir (Hills ve diğerleri, 2012).Y nesli 80-90 yıllarında ilk ve çoğu zaman da tek çocuğa sahip olan ve anılan dönemde Türkiye'ye giren çok uluslu şirketlerin cömert maaş politikaları sayesinde zenginleşen ebeveynler tarafından, istedikleri her işi 
yapabilecekleri yönünde güven aşılanarak ve 'sınırsız toleransla' büyütülmüşlerdir (Yüksekbilgili, 2013).

Esasen hem yetiştirilme tarzları hem de gençlik dönemlerinde yaşadıkları ortak deneyimlerin etkili olduğu söylenebilir. Erikson, bir bireyin karakterinin geriye dönülemez biçimde çocuklukta biçimlenmediğine, aksine yaşamın her evresinde derin gelişmelere sahne olduğuna inanır. Erikson'a göre kimlik, “kişinin sürekli ve değişmez nitelikteki kendi yaşantısıdır, hem kişinin iç dünyasındaki bütünlüğü, hem de dış dünyayla ilişkisini, toplumsal ve kültürel örgütlenişe katılımını belirler"(Elkind, 1978).

\section{Literatür Araştırması}

Y neslineliteratürde farklı isimler verilmektedir. Bunlardan bazıları;Nexters, MillenyumNesli, NintendoNesli, Dijital Yerliler (Gerke, 2001; Gardner, 2006; Weston 2006), EchoBoomers, Boomlets, I Nesli, Netizens' dir (Hutchinson, 2012). Ayrica Facebook Nesli ad1 da verilmektedir (Quinn, 2010).Aşağıdaki tabloda farklı akademisyenler tarafından çeşitli tarihlerde yapılan sinıflamalar görülmektedir.

Sessiz Kuşak: Savaş nesli adı da verilen bu kuşak 1925-1945 yılları arasında dünyaya gelenlerin üyesi olduğu nesildir. Bu dönemin dünya çapındaki en önemli hadiseleri İkinci Dünya Savaşı ve ekonomik buhranlardır. Bu yıllar Türkiye'de ise Cumhuriyet Dönemi'nin tek partili olduğu yıllara denk gelmektedir. Çağımızın büyükleri olarak bu kuşak üyeleri, tartışmacı, çıkarım yapabilen ve süreç odaklı olmakla birlikte, karar vermekte oldukça sıkıntı çeken bireylerdir. Bu neslin üyeleri otoriteye karşı sadıktırlar ve direktif beklerler.Denge ve düzeni tercih eder. Liderlerine yüksek saygı gösterir ve gelenekçidirler. Teknolojiye yavaş uyum gösterir. Kıdemi yaşla ilişkilendirirler.

Baby Boomers (Bebek Patlaması Nesli): Baby Boomers 1946-1964 (Pekala, 2001), 1944-1960 (Arsenault, 2004) ve 1943-1960 (Families \&Work Institute, 2002) yılları arasından doğan kuşak olarak tanımlanmaktadır. 1946 yılında sona eren İkinci Dünya Savaşı ve 1964 yıllarında ABD'de düşmeye başlayan doğum oranları ile Baby Boomers'ın zaman aralığı literatürde genellikle 1946-1964 yılları arası olarak kabul edilmektedir.

Tablo 1. Kaynak Sınıflandırma Tablosu 


\begin{tabular}{|c|c|c|c|c|c|}
\hline Howe\&Straus (2000) & $\begin{array}{l}\text { Sessiz Kuşak } \\
(1925-1943)\end{array}$ & $\begin{array}{l}\text { Patlama Nesli } \\
(1943-1960)\end{array}$ & $\begin{array}{c}\text { 13. Kuşak } \\
\text { (1961-1981) }\end{array}$ & $\begin{array}{c}\text { Milenyum Nesli } \\
(1982-2000)\end{array}$ & - \\
\hline $\begin{array}{l}\text { Lancaster\&Stillman } \\
\qquad(2002)\end{array}$ & $\begin{array}{l}\text { Gelenekçiler } \\
(1900-1945)\end{array}$ & $\begin{array}{c}\text { Bebek } \\
\text { Patlaması } \\
(1946-1964)\end{array}$ & $\begin{array}{l}\text { X Nesli (1965- } \\
\text { 1980) }\end{array}$ & $\begin{array}{c}\text { Milenyum Nesli } \\
\text { Patlama Kopyası } \\
\text { Y Nesli } \\
\text { Y Nesli } \\
\text { (1981-1999) }\end{array}$ & - \\
\hline $\begin{array}{l}\text { Martin\&Tulgan } \\
\qquad(2002)\end{array}$ & $\begin{array}{l}\text { Sessiz Kuşak } \\
(1925-1942)\end{array}$ & $\begin{array}{c}\text { Bebek } \\
\text { Patlaması } \\
(1946-1960)\end{array}$ & $\begin{array}{l}\text { X Nesli (1965- } \\
\text { 1977) }\end{array}$ & $\begin{array}{l}\text { Milenyumlar } \\
(1978-2000)\end{array}$ & - \\
\hline $\begin{array}{c}\text { Oblinger\&Oblinger(2 } \\
005)\end{array}$ & $\begin{array}{l}\text { Yetişkinler } \\
(<1946)\end{array}$ & $\begin{array}{c}\text { Bebek } \\
\text { Patlaması } \\
(1947-1964)\end{array}$ & $\begin{array}{l}\text { X Nesli (1965- } \\
\text { 1980) }\end{array}$ & $\begin{array}{c}\text { Y Nesli } \\
\text { Net Nesli } \\
\text { Milenyumlar } \\
\text { (1981-1995) }\end{array}$ & $\begin{array}{c}\text { Milenyum } \\
\text { Sonrası } \\
\text { (1995-şimdi) }\end{array}$ \\
\hline Topscott (1998) & - & $\begin{array}{c}\text { Bebek } \\
\text { Patlaması } \\
(1946-1964)\end{array}$ & $\begin{array}{l}\text { X Nesli (1965- } \\
\text { 1975) }\end{array}$ & $\begin{array}{l}\text { Dijital Kuşak (1976- } \\
\text { 2000) }\end{array}$ & - \\
\hline Zemke vd. (2000) & $\begin{array}{l}\text { Eski Askerler } \\
(1922-1943)\end{array}$ & $\begin{array}{c}\text { Bebek } \\
\text { Patlaması } \\
(1943-1960)\end{array}$ & $\begin{array}{l}\text { X Nesli (1960- } \\
\text { 1980) }\end{array}$ & $\begin{array}{c}\text { Gelecektekiler } \\
(1980-1999)\end{array}$ & - \\
\hline
\end{tabular}

$\mathrm{Bu}$ neslin Amerika Birleşik Devletleri'ndeki belirleyici olayları, ABD Başkanı John F. Kennedy'nin vurulması, dünyadaki kadın hakları ve insan hakları hareketleri, Ay'a seyahat ve Vietnam Savaşı'dır. Vietnam Savaşı özellikle ABD’de Sessiz Kuşak ile Baby Boomers arasındaki en belirleyici olay olarak görülmektedir.

X Nesli: X Nesli, çeşitli kaynaklarda 1965-1978 (Pekala, 2001), 1961-1980 (Arsenault, 2004) ve 1965-1979 (Families and Work Institute: 2002) yılları arasında doğan kuşak olarak tanımlanmaktadır. Bu neslin üyeleri bir önceki kuşaktan farklı olarak cinsiyet rollerinde ve aile yapılarında değişimlere tanık olmuşlardır. Genellikle çalışan ebeveynlerin çocuklarıdırlar, ebeveynleri olmadan kendi başlarına okuldan eve gidip gelerek kendi başlarına büyümeyi öğrenmişlerdir. Bu dönemde Türkiye'de ise; petrol krizleri, ekonomik sarsıntılar, 68 nesli, üniversite olayları, sol-sağ çatışması ve televizyon ,(televizyonun evlere 
girişi ile birlikte çok daha fazla şiddet ve negatif olay da evlerden izlenebilir olmuştur) dönemin en önemli olgularıdır (Mengi, 2011).

Y Nesli: Y Nesli, çeşitli kaynaklarda 1981-2000 (Arsenault, 2004), 1980-günümüz (Families and Work Institute, 2002) ve 1979-2001 (Pekala, 2001), 1982-2004 (Howe\&Strauss 1992) y1llar1 arasında doğan kuşak olarak tanımlanmaktadır.

Y neslikavramı ilk defa 1993 yılında o zamanın ergenlik çağındaki gençlerinin önceki X neslindenfarkllarını ortaya koymak için kullanılmıştır (Howe\&Strauss 1992). İngilizce WHY kelimesinden gelen $\mathrm{Y}$ harfi esasen sorgulayıcı yapılarından dolayı bu kuşağıtanımlamak için kullanılmıştır.ABD'deki, 11 Eylül 2001 saldırılarını, silahlı okul baskınlarını televizyondan izleyerek büyüyen bu neslin kahramanları, polis memurları, itfaiyeciler ve belediye başkanları olmuştur. Bu kuşakta Vietnam Savaşı'ndan sonra azalma gösteren vatanseverlik duyguları yeniden canlanmıştır (Pekala, 2001). Türkiye'de ise bu nesli etkileyen dönemin başlıca olayları; artan terör eylemleri, Körfez Savaşı, Irak Savaşı, internet, küreselleşen dünya, sosyal medya ve cep telefonu olmuştur.

Y Nesli da, X Nesli gibi çalışan anne babaya sahiptir. Ancak ebeveynlik yaşı yükselmiştir. Ebeveynleri önceki kuşak ebeveynlerden çok farklı olan bu kuşak, çocuğunun iyi şartlar altında büyüyebilmesi, iyi bir eğitim alması ve güvende olması konusunda çok daha aktif rollere sahip anne babalara sahiptir.İş, eğlence ve sosyal aktiviteler iç içe geçmiştir. Çeşitlilik ile büyüyen bu kuşak, nerdeyse yok sayacak ölçüde insanlar arasındaki etnik farklılıkları dikkate almamaktadırlar (Notter, 2005). Bu yönüyle X neslinden farklıdır.

Y kuşağı bireyleri sosyal bilinci olan, insan ilişkilerine odaklı, işbirliğine yatkın ve öğrenme isteğiyüksek kişiler olarak nitelenmektedirler. Bu kuşak mensupları yaptıkları işin açık ve net talimatlar içermesini, iş performans değerlendirmelerininyüz yüze yapılmasını, iş ile ilgili fikirlerinin sorulmasını ve yönetimekatılmayı istemektedirler (McEwan,2009).Bu kuşak mensuplarıkarmaşık işlerdenhoşlanır ve kendini geliştirebileceği bir kariyeri olmasını isterler. Rutin bir iş yerinekarmaşık bir işi tercih ederler ve bu istekleri karşılanmadığında iş değiştirmeyi tercih edebilirler. Önceki kuşaklara göre daha çabuk iş değiştirebilirler. İşten ayrılma nedenlerinden en önemlileri o pozisyonda gelecek ve gelişme imkanı görmemeleridir.Y nesliçalışanlar hedefledikleri kariyer pozisyonlarına ulaşana kadar iş değiştirebileceklerine inanırlar(Kelanvd.,2009). Bu nedenle insan kaynağı yapılanmasında verimlilik hedefleyen firmaların iş süreçlerini yeni neslin özelliklerine göre şekillendirdiklerini görmekteyiz. Bu firmalar iş süreçlerini yeni nesle uydururken yurt dişı örnekleri aynen uygulamak yerine Türkiye' deki Y neslinin kültürel özelliklerine göre bir uyarlama yaparlarsa daha başarılı sonuçlar elde edeceklerdir (Yüksekbilgili Z.,2013). 
Lower' a göre Y Nesli mensupları çoklu görevlere kolayca uyum sağlamaktadırlar (Lower, 2008). Ayrıca sabırsız (Sheahan, 2005), çok kültürlü ve küresel bakış açısına sahiptirler (Weston, 2006). Twenge\&Campbell'e göre $\mathrm{Y}$ nesli kendini beğenmiş ve narsist olarak nitelendirilebilmektedir. Ayrıca kolayca iş değiştirebilmektedirler (Twenge\&Campbell, 2008). Sıra dışı bir düşünce yapıları vardır.İş hayatında kariyer basamaklarını hızla yükselmek isterler ve yüksek maaş beklentileri vardır. Esnek çalışma olan iş yerlerini tercih etmektedirler (Hogg, 2012). Başarı odaklılardır (Woodvd, 2008). Y neslini oluşturan bireyler özgürlüklerine düşkün ve teknoloji tutkunu olarak tanımlanabilir. Rahat yaşamaya çok önem veririler, teknoloji hayatlarının merkezinde yer almaktadır. Piyasaya yeni çıkan ürünleri hızla tüketirler. Türkiye'de yaşayan kişilerin yüzde 25'ini bu kuşak oluşturmaktadır (Yasa ve Bozyiğit, 2012). Türkiye'de iş dünyasında iş gücünün yarısını Y neslinde bulunan çalışanlar oluşturmaktadır. Bu oran çağrı merkezi sektöründe\%83'e, e-Ticaret sektöründe ise \%79'a ulaşmaktadır. 2012 yılı itibariyle Türkiye' de yönetim pozisyonlarının \%3,3' nün Y nesli tarafından doldurulduğu görülmektedir. $Y$ neslinin temel değerleri aşağıdaki gibidir (HayGroup, 2012):

- Kendine güvenleri yüksektir.

- Başarmak için azimle çalışırlar.

- Rekabetçilerdir.

- İşbirliğine açıktır.

- Kavganin yanı sira, uzlaşma yolunu tercih ederler.

- Yaptığ işin toplumsal değerlerle uyumuna önem verirler.

- Rutini sevmez, "değişimi" hayatının normal bir parçası olarak algılar, hatta "değişimi" isterler.

- Yaratıcıdır, "orantısız" bir hayal gücüne sahiptir.

- Çalıştığı şirkete bağlılı̆̆g-aidiyeti düşüktür.

Y nesli mensubu çalışanların işten ayrılmasının önlenmesinde en önemli faktör şirket itibarı ve imajıdır. Ayrıca kariyer ve gelişim fırsatlarıda önemli unsurlardan biridir (HayGroup, 2012).Small' a göre Y neslinin özelliklerini listelersek (Small, 2009):

- Aynı anda pek çok iş yapabilirler, çapraz işlemleri rahatlıkla tamamlarlar. Örneğin, televizyon izlerken diğer medya araçlarını, özelliklede interneti kullanmaktadırlar.

- Özellikle geleneksel öğrenme yöntemleriyle karşılaştıklarında dikkat süreleri kısadır.

- Kendilerine ait sanal görgü kuralları ve dilleri bulunmaktadır.

- Okumaya ayırdıkları zaman çok azdır. Fakat erken yaşta okuma ve yazma öğrenmişlerdir.

- Dil gelişimleri ise zayıftır. Kendilerini daha çok internet ortamında ifade edebilirler.

- Geleneksel öğrenme yöntemlerine uyum sağlayan sinirsel akım ve beynin bazı bölümleri yeterince gelişmemiştir.

- Beyinleri hızlı sanal aramalar için yapılanmış durumdadır. 
- Mahremiyet duyguları zayıftır. Özel düşünce ve duygularını internet sitelerinde arkadaşlarıyla -hatta yabancılarla- paylaşmayı tercih ederler.

- Gürültülü ortamlarda dijital yerlilere göre daha rahat çalışırlar.

\section{Metodoloji}

\section{Araştırmanın Amacı}

$\mathrm{Bu}$ araştırmada, öncelikle $\mathrm{Y}$ neslinin örgüt ortamında diğerlerinden farklılaştığı boyutların belirlenmesi ve bu boyutların hangi yönde farklılaştıklarının analizi amaçlanmıştır.

\section{Örneklem ve Veri Toplama Yöntemi}

Örgüt ortamında Y neslinin diğer nesillerden hangi davranış boyutlarında ne yönde farklılaştığını tespit etmeyi amaçlayan bu çalışmada öncelikle Türkiye'de faaliyet gösteren firmaların üst düzey yöneticilerinden oluşan 92 kişiye açık uçlu sorular sorularak $Y$ nesli çalışanlarla ilgili görüşlerini paylaşmaları istenmiştir. Bu ön anketlerin incelenmesi sonucunda, nesiller arası farklılaşmanın olabileceği muhtemel boyutlar tespit edilmiştir. Sonrasında literatür araştırması yapılarak bu boyutların ölçekleri literatüre uygun şekilde oluşturulmuştur. Bu ölçekler doğrultusunda oluşturulan anket sorularını içeren anket, 121 tanesi Y neslinden oluşan toplam 196 çalışana uygulanmıştır. 17 boyutla başlayan çalışma 9 boyuta indirgenerek nihai analize uygun hale getirilmiştir.

\section{Ölçekler}

Araştırmamızda belirlenen boyutların soruları ise, boyut bazında literatürde geçerliliği ve güvenilirliği test edilmiş testlerden veya çeşitli yayınlardan derlenmiştir. Ölçek 46 adet sorudan oluşmuştur. Bu sorular daha önce boyutları oluşturmada katkı istenen şirket yöneticilerinin çalışanlarına yöneltilmiştir. Özgüven boyutu; kendini ortaya koyma ve ifade etme becerisini,çoklu görev boyutu; aynı anda birden fazla işle ilgilenebilme becerisini sosyal medya kullanma boyutu, sosyal medyayı kullanma sıklığı ve kullanma becerisini belirtmektedir. Özgüven boyutunu, çoklu görev boyutunu, sosyal medya kullanma boyutunu ölçmek için;Small\&Vorgan(2009) ölçeği kullanılmıştır. Yaratıcılık boyutu, ilginç ve kullanılabilir fikirler üretebilmek olup, yaratıcılık boyutunu ölçmek için Schwartzvd, (2001) ölçeğikullanılmıştır. Takım çalışmasına yatkınlık boyutu; ‘belirli bir amacı paylaşan ve birbirlerini tamamlayıcı yeteneklere sahip olan az sayıda insandan oluşan bir toplulukta uyumlu bir şekilde çalışabilme becerisini ve takım çalışmasına yatkınlık boyutunu ölçmek için Levi\&Slem(1995) kullanılmıştır. Eğlenerek çalışma boyutu; 'çalışanların moralini yüksek tutan keyifli bir çalışma platformu oluşturmak've ölçmek için Berg(2011) ölçeği kullanılmıştır.Sorumluluk duygusu; kişilerin ne kadar düzenli, disiplinli, organize ve başarı 
odaklı oldukları ile ilişkilidir (McCrea\&Costa,2003) ve sorumluluk boyutunu ölçmek için Goldberg (1990) IPIP(Personality Inventory Scale) ölçeği kullanılmıştır. Klasik giyim anlayışının tanımı, iş yerinde formal giyim tarzından hoşlanılmaması ve kıyafet zorunluluğu olmayan iş alanlarının özellikle tercih edilmesidir, boyutun soruları ise, çalışma ekibi tarafından tasarlanmıştır. Örgütsel bağlılık, personelin örgütle ilişkisini şekillendiren ve örgütte kalıcı olma kararı almalarını sağlayan bir davranıştır. Klasik giyim anlayışı boyutunu ölçmek için kullanılan ölçek, firmaların üst düzey yöneticileri ile yapılan görüşmeler ve akademik değerlendirmeler göz önünde bulundurularak araştırma grubumuz tarafından geliştirilmiştir. Örgütsel bağlllık boyutunu ölçmek için Allen\&Meyer(1993) ölçeği kullanılmıştır.

Tablo 2. Boyut Tablosu

\begin{tabular}{|c|c|c|}
\hline Boyut & Tanım & Ölçek \\
\hline Özgüven & Kendini ortaya koyma ve ifade etme becerisi & Small\&Vorgan, 2009 \\
\hline Çoklu Görev & Aynı anda birden fazla işle ilgilenebilme becerisi & Small\&Vorgan, 2009 \\
\hline $\begin{array}{l}\text { Sosyal Medya } \\
\text { Kullanımı }\end{array}$ & Sosyal medyayı kullanma sıklığı ve kullanma becerisi & Small\&Vorgan, 2009 \\
\hline Yaratıcılık & ïlginç ve kullanılabilir fikirler üretebilmek & $\begin{array}{l}\text { Schwartz\&Owens, } \\
2001\end{array}$ \\
\hline Örgütsel Bağlılık & $\begin{array}{l}\text { Personelin örgütle ilişkisini şekillendiren ve örgütte } \\
\text { kalıcı olma kararı almalarını sağlayan bir davranıştır. }\end{array}$ & Meyer\&Allen,1996 \\
\hline $\begin{array}{l}\text { Takım Çalışmasına } \\
\text { Yatkınlık }\end{array}$ & $\begin{array}{l}\text { Belirli bir amacı paylaşan ve birbirlerini tamamlayıcı } \\
\text { yeteneklere sahip olan az sayıda insandan oluşan bir } \\
\text { toplulukta uyumlu bir şekilde çalışabilme becerisi }\end{array}$ & Levi\&Slem, 1995 \\
\hline Eğlenerek Çalışma & $\begin{array}{l}\text { Çalışanların moralini yüksek tutan keyifli bir çalışma } \\
\text { platformu oluşturmak }\end{array}$ & Berg, 2011 \\
\hline Sorumluluk & $\begin{array}{l}\text { Kişilerin ne kadar düzenli, disiplinli, organize ve başarı } \\
\text { odaklı oldukları ile ilişkilidir. }\end{array}$ & Goldberg, 1999 \\
\hline Giyim Anlayışı & $\begin{array}{l}\text { İş yerinde formal giyim tarzından hoşlanılmaması ve } \\
\text { kıyafet zorunluluğu olmayan iş alanlarının özellikle } \\
\text { tercih edilmesi }\end{array}$ & $\begin{array}{l}\text { Araştırma Grubu, } \\
\qquad 2014\end{array}$ \\
\hline
\end{tabular}




\section{Deneysel Analiz Ve Sonuçlar}

\section{Faktör Analizi}

Y neslini diğer nesillerden ayıran özelliklerin tespit edilmesi için literatürden yararlanarak oluşturduğumuz anketin ölçek geçerliğinin tespit edilmesi için öncelikle doğrulayıcı faktör analizi yapılmış ve 9 boyutta ölçek geçerliğinin olduğu anlaşılmıştır. Bu analizde sırasıyla aşağıdaki sonuçlara ulaşılmıştır.

Tüm bağımsız değişkenler analize dahil edilerek Principal Component Analysis (PCA) yapılmıştır. Öncelikle analize dahil edilen soruların faktör analizine uygunluğunu ölçmek için Anti-imajkorelasyon matrisinde yer alan MSA (Measure of Sampling Adequacy) değerlerine bakılmıştır. Anti-imajkorelasyon matrisinde diyagonal olarak yer alan değerlerin hepsi 0,50 değerine yakın veya üzerinde olduğundan boyutların faktör analizine uygun olduğu tespit edilmiştir.

Yapılan faktör analizi sonucunda 9 faktör elde edilmiş olup, modeldeki toplam değişimin açılanma oranının \% 77 olduğu tespit edilmiş ve kullanılan verinin değişkenlerin homojen gruplaşması olduğunu gösteren 0,676 değerinde Kaiser-Meyer-Olkin (KMO) ve anlamlı bir Barlett küresellik testi sonucu elde edilmiştir. Bu bulgular değişkenler arasında faktör analizi yapmaya yeterli düzeyde bir ilişki olduğunu göstermektedir. Analiz sonucunda elde edilen Döndürme Faktör Matrisinin (Rotated Component Matrix) faktör yapısı Tablo 3'de özetlenmiştir.

Tablo 3. Döndürme Faktör Matrisi (RotatedComponent Matrix)

\begin{tabular}{|l|c|c|c|c|c|c|c|c|c|}
\hline \multicolumn{1}{|c|}{ Sorular } & $\mathbf{1}$ & $\mathbf{2}$ & $\mathbf{3}$ & $\mathbf{4}$ & $\mathbf{5}$ & $\mathbf{6}$ & $\mathbf{7}$ & $\mathbf{8}$ & $\mathbf{9}$ \\
\hline Eğlenerek Çalışma & & & & & & & & & \\
\hline Soru 1 &, 799 & & & & & & & & \\
\hline Soru 2 &, 909 & & & & & & & & \\
\hline Soru 3 &, 809 & & & & & & & & \\
\hline Soru 4 & & & & & & & & & \\
\hline $\begin{array}{l}\text { Takım Çalışmasına } \\
\text { Yatkınlık }\end{array}$ & &, 703 & & & & & & & \\
\hline Soru 1 & &, 919 & & & & & & & \\
\hline Soru 2 & & & & & & & & \\
\hline
\end{tabular}


AJIT-e: Online Academic Journal of Information Technology

2014 Spring/Bahar - Cilt/Vol: 5 - Sayı/Num: 15

DOI: 10.5824/1309-1581.2014.2.004.x

\begin{tabular}{|c|c|c|c|c|c|c|c|c|}
\hline Soru 3 & ,839 & & & & & & & \\
\hline \multicolumn{9}{|l|}{ Giyim } \\
\hline Soru 1 & & ,895 & & & & & & \\
\hline Soru 2 & & 916 & & & & & & \\
\hline \multicolumn{9}{|c|}{$\begin{array}{l}\text { Sosyal Medya } \\
\text { Kullanımı }\end{array}$} \\
\hline Soru 1 & & & ,889 & & & & & \\
\hline Soru 2 & & & ,883 & & & & & \\
\hline \multicolumn{9}{|c|}{ Çoklu Görev } \\
\hline Soru 1 & & & & ,852 & & & & \\
\hline Soru 2 & & & & 811 & & & & \\
\hline \multicolumn{9}{|c|}{ Sorumluluk } \\
\hline Soru 1 & & & & & ,784 & & & \\
\hline Soru 2 & & & & & ,861 & & & \\
\hline \multicolumn{9}{|c|}{ Örgütsel Bağlılık } \\
\hline Soru 1 & & & & & & 819 & & \\
\hline Soru 2 & & & & & & 828 & & \\
\hline \multicolumn{9}{|c|}{ Yaratıcılık } \\
\hline Soru 1 & & & & & & & 821 & \\
\hline Soru 2 & & & & & & & ,783 & \\
\hline \multicolumn{9}{|c|}{ Özgüven } \\
\hline Soru 1 & & & & & & & & ,856 \\
\hline Soru 2 & & & & & & & & ,629 \\
\hline
\end{tabular}




\section{Güven Analizi}

Yapılan faktör analizi sonucunda oluşan 9 faktörün iç güvenilirliklerinin ölçülmesi amacıyla Güvenilirlik Testi yapılmıştır. Bu kapsamda faktörlerin iç güvenilirliği Cronbach's Alpha değerleri hesaplanarak tespit edilmiştir.

Yapılan analiz sonucunda Cronbach's Alpha değerleri genel olarak 0,705 olarak bulunduğu için kabul gören 0,70 değerinin üzerindedir. Bu durumda boyutların iç güvenilirliğinin yeterli seviyede olduğu tespit edilmiştir. Analiz sonuçlarında 9 faktör arasından herhangi bir sorunun çıkarılması iç güvenilirlik değerlerine önemli bir katkı sağlamadığı için, soru eksiltilmesini gerektirecek bir bulguya rastlanmamıştır. Güvenilirlik testi yapılan faktörlere ait analiz sonuçları Tablo 4' de özetlenmiştir.

Tablo 4. Güvenilirlik Analizi (Reliability Analysis)

\begin{tabular}{|c|c|c|c|}
\hline Sorular & $\begin{array}{l}\text { Soru Silindiğinde } \\
\text { Ölçek Ortalaması }\end{array}$ & $\begin{array}{c}\text { Soru Silindiğinde Ölçek } \\
\text { Varyansı }\end{array}$ & $\begin{array}{c}\text { Soru Silindiğinde } \\
\text { Cronbach Alfa Değeri }\end{array}$ \\
\hline \multicolumn{4}{|l|}{ Özgüven } \\
\hline Soru 1 & 75,9796 & 53,630 & ,719 \\
\hline Soru 2 & 76,2704 & 51,080 & ,702 \\
\hline \multicolumn{4}{|l|}{ Çoklu Görev } \\
\hline Soru 1 & 76,4490 & 48,505 & ,692 \\
\hline Soru 2 & 77,0969 & 48,098 & ,694 \\
\hline \multicolumn{4}{|l|}{ Sosyal Medya } \\
\hline Soru 1 & 76,6378 & 48,663 & ,695 \\
\hline Soru 2 & 76,9235 & 48,553 & ,699 \\
\hline \multicolumn{4}{|l|}{ Yaratıcılık } \\
\hline Soru 1 & 75,7755 & 51,734 & 698 \\
\hline Soru 2 & 76,0051 & 50,190 & ,693 \\
\hline \multicolumn{4}{|l|}{ Takım Çalışması } \\
\hline Soru 1 & 75,8112 & 50,113 & 689 \\
\hline Soru 2 & 75,5867 & 49,700 & ,685 \\
\hline
\end{tabular}




\begin{tabular}{|c|c|c|c|}
\hline Soru 3 & 75,5612 & 49,591 & ,684 \\
\hline \multicolumn{4}{|l|}{ Bağlılık } \\
\hline Soru 1 & 76,3673 & 50,582 & 699 \\
\hline Soru 2 & 76,2857 & 52,349 & 714 \\
\hline \multicolumn{4}{|c|}{ Eğlenerek Çalışma } \\
\hline Soru 1 & 75,9898 & 47,559 & ,677 \\
\hline Soru 2 & 75,6939 & 47,731 & ,674 \\
\hline Soru 3 & 75,7908 & 47,233 & ,673 \\
\hline Soru 4 & 75,9184 & 47,029 & ,677 \\
\hline \multicolumn{4}{|c|}{ Sorumluluk } \\
\hline Soru 1 & 75,8214 & 50,496 & ,692 \\
\hline Soru 2 & 76,0204 & 50,112 & 691 \\
\hline \multicolumn{4}{|l|}{ Giyim } \\
\hline Soru 1 & 77,1786 & 51,388 & ,716 \\
\hline Soru 2 & 77,4490 & 52,361 & ,717 \\
\hline
\end{tabular}

\section{Bağımsız Örneklem t- Testi}

Uygulanan doğrulayıcı faktör analizi ve güvenilirlik analizleri vasıtasıyla sırasıyla ölçek geçerliliği ve güvenilirliği tespit edilen 9 boyutta $\mathrm{Y}$ neslini diğer nesillerden ayıran özelliklerin tespit edilmesi için $\mathrm{Y}$ nesline mensup olanlar ve diğerleri arasında her boyut için bağımsız örneklem t-testi uygulanmıştır. Bu suretle her boyut için ortalama farklarının anlamlılık düzeyleri tespit edilmiştir. 
Tablo 5. Bağımsız Örneklem T-Testi

\begin{tabular}{|c|c|c|c|c|c|}
\hline \multirow{2}{*}{ Boyutlar } & \multicolumn{2}{|c|}{ Levene Test Sonucu } & \multicolumn{3}{|c|}{ T Testi Sonucu } \\
\hline & $\mathbf{F}$ & Sig. & $\mathbf{t}$ & df & Sig. \\
\hline \multirow{2}{*}{ Özgüven } & ,350 & ,555 & ,332 & 194 & ,740 \\
\hline & & & ,328 & 151,349 & ,743 \\
\hline \multirow{2}{*}{ Çoklu Görev } & 2,838 & ,094 & $-3,326$ & 194 & ,001 \\
\hline & & & $-3,222$ & 141,073 & ,002 \\
\hline \multirow{2}{*}{$\begin{array}{l}\text { Sosyal Medya } \\
\text { Kullanımı }\end{array}$} & ,129 & ,719 & $-3,709$ & 194 & 000 \\
\hline & & & $-3,679$ & 152,830 & 000 \\
\hline \multirow{2}{*}{ Yaratıcılık } & ,754 & ,386 &,- 871 & 194 & ,385 \\
\hline & & &,- 845 & 142,175 & ,399 \\
\hline \multirow{2}{*}{ Takım Çalışması } & 1,505 & ,221 & $-1,959$ & 194 & ,052 \\
\hline & & & $-1,892$ & 139,644 & 061 \\
\hline \multirow{2}{*}{ Bağlılık } & ,335 & ,564 & 1,832 & 194 & ,068 \\
\hline & & & 1,806 & 149,691 & ,073 \\
\hline \multirow{2}{*}{ Eğlenerek Çalışma } & 5,126 & 025 & $-2,224$ & 194 & 027 \\
\hline & & & $-2,029$ & 114,805 & 045 \\
\hline \multirow{2}{*}{ Sorumluluk } & 093 & ,760 & $-1,560$ & 194 & 120 \\
\hline & & & $-1,494$ & 135,685 & 137 \\
\hline \multirow{2}{*}{ Giyim } & 058 & 809 & ,753 & 194 & 452 \\
\hline & & & 754 & 157,143 & 452 \\
\hline
\end{tabular}

Yapılan bağımsız örneklem t-Testi sonuçları Tablo 5' de özetlenmiştir. Analiz sonuçlarına göre "Çoklu Görev”, “Sosyal Medya Kullanma”, “Takım Çalışmasına Yatkınlık”, “Örgütsel Bağllık" ve "Eğlenerek Çalışma" boyutlarında Y nesli çalışanların diğer çalışanlardan ayrıştı̆̆1 tespit edilmiştir. 
Tablo 6. Ortalama Farkı Tablosu

\begin{tabular}{|c|c|c|c|}
\hline Boyutlar & Nesiller & $\begin{array}{c}\text { Örneklem } \\
\text { Sayısı }\end{array}$ & Ortalama \\
\hline \multirow{2}{*}{ Çoklu Görev } & Diğerleri & 75 & 2,9667 \\
\hline & Y Nesli & 121 & 3,4380 \\
\hline \multirow{2}{*}{ Sosyal Medya Kullanımı } & Diğerleri & 75 & 2,9067 \\
\hline & Y Nesli & 121 & 3,4628 \\
\hline \multirow{2}{*}{ Takım Çalışması } & Diğerleri & 75 & 4,2756 \\
\hline & Y Nesli & 121 & 4,4408 \\
\hline \multirow{2}{*}{ Bağ|ılık } & Diğerleri & 75 & 3,8333 \\
\hline & Y Nesli & 121 & 3,6240 \\
\hline \multirow{2}{*}{ Eğlenerek Çalışma } & Diğerleri & 75 & 4,0267 \\
\hline & Y Nesli & 121 & 4,2789 \\
\hline
\end{tabular}

Tablo 6'da görüldüğü gibi Y nesli çalışanları "Çoklu Görev", "Sosyal Medya Kullanma", “Takım Çalışmasına Yatkınlık", ve "Eğlenerek Çalışma” boyutlarında diğerlerine göre daha yüksek ortalama değerine sahiptir. Fakat "ÖrgütselBağl1lık” boyutunda Y nesli çalışanların ortalamaları düşük bulunmuştur.

\section{Tartışma}

\section{Teorik Katkıları}

Araştırmada yapılan 9 boyut için faktör, güven analizi sonrası uygulanan T testi ile 5 boyutta Y neslinin diğerlerinden anlamlı bir şekilde farklılaştığ 1 bulunmuştur. Bu boyutlar; çoklu görev, sosyal medya kullanımı, takım çalışmasına yatkınlık, örgütselbağlılık, eğlenerek çalışma boyutlarıdır.

Özgüven, yaratıcılık, sorumluluk, giyim boyutlarında ise nesiller arasındaki farklılığın anlamlı olmadığı görülmüştür. Tablo 6’da da görüldüğü üzere, Y nesli çalışanları, çoklu görev, sosyal medya kullanımı, takım çalışmasına yatkınlık, eğlenerek çalışma boyutlarında 
diğer çalışanlara göre yüksek ortalama değerlerine sahiptir. Fakat örgütselbağl1lıkboyutunda daha düşük ortalama değere sahiptirler.

\section{Yönetimsel Katkıları ve İleri Araștırma}

Bu çalışmanın yönetsel katkısı olarak ele alınabilecek en önemli sonuç, Y nesli çalışanlarının iyi bir takım oyuncusu oldukları ve örgüt içinde bu pozisyonlarda değerlendirilmelerinin daha verimli sonuçlar doğurabileceğidir. Bir diğer yönetsel katkı ise, bu bireylerin örgüt bağlılıklarının arttırılabilmesi için diğerlerine göre daha çok çaba gerektiğidir. Bu aşamada Y nesli çalışanların örgütsel bağlılığının nasıl arttırılacağına yönelik bilimsel çalışmalar ileri araştırma konusu olarak önerilmektedir. Eğlenerek çalışma ve sosyal medya boyutlarındaki yüksek ortalamalar dikkate alınarak $\mathrm{Y}$ nesli çalışanların bulunduğu iş ortamlarında sosyal aktivitelerin artırılması ve çalışma saatleri içerisinde dahi sosyal medya kullanımının yasaklanmaması önerilmektedir. Çoklu görev boyutunun, sahip olduğu ortalama göze alınarak bu kişilerin iş zenginleştirme uygulamaları durumunda motivasyonlarının artırılacağı öngörülerek, bir ileri araştırma konusu olarak ele alınabilir.

\section{Sinırlamalar}

Elde edilen sonuçlarla ilgili bazı sınırlandırmalar bulunmaktadır. Öncelikle araştırmanın ana kütlesi değişik sektörlerden olmasına rağmen örneklem sayısının düşük olması ve Y nesli çalışanları ile diğerlerinin eşit olmaması karşılaştırma açısından bir kısıt olarak görülebilir.

\section{Kaynakça}

ALLEN N., MEYER J. (1993),Commitment to organizations and occupations: Extension and test of a three-component conceptualization', Journal of Occupational Psychology,78,538-551.

ARSENAULT, P., M.: 2004 'Validating Generational Differences' The Leadership and Organizational Development Journal, Vol.25/2, pp.315.

BERG D. H., (2011). The power of a playful spirit at work. The Journal for Quality and Participation, $24,57-62$.

ELKIND, D. (1978). Understanding the young adolescent. Adolescence, 13, 127-134.

ERIKSON, E.H. (1980). Identity and the Life Cycle.NewYork:W.W. Norton\&Company,Inc.,

FAMILIES AND WORK INSTITUTE: Generation and Gender in the Workplace, 2002, www.familiesandwork.org

GARDNER S.F. (2006). 'Preparing for the Nexters'. American Journal of Pharmaceutical Education 70 (4), 1. 
GERKE M.L. (2001). “Understanding and leading the quad matrix: four generations in the workplace: the Traditional Generation, Boomers, Gen X, Nexters". Seminars for Nurse Managers 9 (3), 173-181.

GOLDBERG (1990), L.R; An Alternative 'Description of Personality' The Big Five Factor Structure, Journal of Personality and Social Psychology, Vol.59, pp. 213-227.

HayGroup, (2012). Üçüncü bin yılda Y nesli işbaşında: Gençler “İş’ e El Koydu. Hay Group Danışmanlık Ltd. Şti.

HILLS C., RYAN S., SMITH D.R. and WARREN H. (2012). “The Impact of Generation Y Occupational Therapy Students on Practice Education”. Australian Occupational Therapy Journal. Vol. 59, pp. 156-163.

HOGG, D. (2012). 'Application of Groupthink to Generation Y Decision Making Processes within a Professional Services Context in New Zealand'. International Journal of Business and Management. Vol. 8, No. 8, pp. 69-79.

HOWE, N., STRAUSS, W, (1992). The New Generation Gap, The Atlantic Monthly, sf:67-89.

HOWE, N.,andSTRAUSS, B. (2000). 'Millennials rising: The next greatest generation'. New York: Vintage Books.

HUTCHINSON, D. (2012). 'Attracting and Maintaining the Y Generation in Nursing: A Literature Review'. Journal of Nursing Management, pp. 444-450.

KELAN, E.L.,GRATTON, L., MAH, A. and WALKER, L., (2009). 'The Reflexive Generation: Young Professionals' Perspectives on Work', Career and Gender. London Business School.

KUPPERSCHMDTH, B. (2000). "Multigeneration employees: Strategies for effective management". The Health Care Manager, 19, pp. 65-76.

LEVID. and SLEMC.(1995).Team work in R\&D organizations: The characteristics of successful teams, International Journal of Industrial Ergonomics, 16, pp.29-42.

LOWER J. (2008). 'Brace yourself here comes generation $Y^{\prime}$. Critical Care Nurse 28 (5), pp. 80-85.

Mc CREA and COSTA,(2003).Personality in Adulthood, New York: Guilford Press.

McEWAN, A.M., (2009). 'Generation Y: Coming to A Workplace Near You.'The Smart Work Company Ltd.

MENGI, Z. (2011)Yazan: Zeynep Mengi Kaynak: www.yenibiris.com/Hürriyet)

MORGAN, C. N. (2011).Generational Differences in the Workplace.

NOTTER J., 2005. 'WhyGenerationsMatter, andWhyTheyDon t: The Business Realitiesof Diversity in theWorkplace'. Financial Management Symposium 
PEKALA, N. :2001 Conqueringthegenerationaldivide. Journalof Property Management. November/December,30-38

QUINN, S. (2010). "Generationalchallenges at theworkplace", Ventus Publishing Aps, www.bookboon.com.

REEVES,T.C.\&OH, E., 2008. 'Generationaldifferences, in handbook of research on educationalcommunicationsandtechnology', . Spector, M.D.Merrill, J.V.Merrienboer, M.P.Driscoll, (Eds.). 3th ed. Athens, Georgia.

SHEAHAN P. (2005). 'Generation Y: ThrivingandSurvivingWithGeneration Y at Work'. Hardie Grant' Melbourne.

SMALL G.and VORGAN G., 'Modern Beynin Evrimi'. (Merve Duygun, Çev.). İstanbul: Omega Yayınlar1. 2009, 1 b, ss. 39-41.

SCHWARTZ, S. H., MELECH, G., LEHMANN, A., BURGESS, S., HARIS, M. and OWENS, V. (2001). Extendingthecross-culturalvalidity of thetheory of basichumanwith a differentmethod of measurement.Journal of Cross-CulturalPsychology, 32 (5), 519-542.

TWENGE J.M. andCAMPBELL S.M. (2008). "Generationaldifferences in psychologicaltraitsandtheirimpact on theworkplace". Journal of ManagerialPsychology. Vol. 23, pp. 862-877.

WESTON M. (2006). 'Integratinggenerationalperspectives in nursing'. Online Journal of Issues in Nursing. 11 (2).

WOOD, J., BAGHURST, T., Waugh, L. \&Lancaster, J. (2008). 'Engagingstudents in theacademicadvisingprocess'. TheMentor: An AcademicAdvisingJournal.

YASA E., BOZYIĞIT S. (2012). 'Y Nesli Tüketicilerinin Cep Telefonu ve GSM Operatörleri Tercihi: Mersin İlindeki Üniversite Öğrencilerinin Tercihlerini Belirlemeye Yönelik Pilot Bir Araştırma'. CagUniversityJournal of SocialSciences, 9(1), s. 33.

YÜKSEKBİLGİLİ Z. 2013 'Türk Tipi YNesli', Elektronik Sosyal Bilimler Dergisi, Vol:12 No:45. 
AJIT-e: Online Academic Journal of Information Technology

2014 Spring/Bahar - Cilt/Vol: 5 - Sayı/Num: 15

DOI: 10.5824/1309-1581.2014.2.004.x 